\title{
Adhesive lamination by EB-irradiation for different polymer sheets applicable for Bio-medical use
}

\section{生体適合使用のための異種高分子材料板の電子線照射による接着複合化}

\section{Hidenori KAWAZU and Hiroaki TAKEI}

Department of Metallurgical Engineering Graduate School of Engineering, Tokai University, 4-1-1 Kitakaname, Hiratsuka, Kanagawa, 259-1292, Japan

TEL:+81-463-58-1211(EX.4206) FAX:x81-463-50-2096 e-mail: Obazm011@mail.tokai-u.jp

\section{Hiroyuki KUDOH and Kohji MITSUBAYASHI}

Department of Biomedical Devices and Instrumentation, Institute of Biomaterials and Bioengineering, Tokyo Medical and Dental University, 2-3-10 Kanda-Surugadai, Chiyoda-ku, Tokyo, 101-0062, Japan TEL: +81-3-5280-8091 FAX: x81-3-5280-8094 e-mail: m.bdi@tmd.ac.jp

\section{Akira TONEGAWA and Yoshitake NISHI}

Graduate School of Science and Technology, Tokai University, 4-1-1 Kitakaname, Hiratsuka, Kanagawa, 259-1292, Japan

TEL:+81-463-58-1211(EX.4206) FAX:x81-463-50-2096 e-mail:am026429@keyaki.cc.u-tokai.ac.jp (Received 29, January 2011 Accepted 14, January 2012 )

The effects of electron beam (EB) irradiation of $0.22 \mathrm{MGy}$ on the adhesive peeling load $\left(L_{\mathrm{p}}\right)$ of composites laminated with polypropylen (PP) and polydimethylsiloxane (PDMS) polymers films were investigated. EB irradiation enhanced the mean $L_{\mathrm{p}}$ from $7.0 \mathrm{mN}$ for untreated composite to $23 \mathrm{mN}$ for $0.22 \mathrm{MGy} \mathrm{EB}$ irradiated one without glue. Since EB irradiation generated dangling bonds with electrons in PP, they probably induced the polarization of terminated atoms of PDMS, as well as enhancement of effective interface area, and then atracted for each polymer at the interface. Results indicated that EB irradiation at $0.22 \mathrm{MGy}$ enhanced the $L_{\mathrm{p}}$, therefore, it was concluded that EB irradiation was probably a useful tool for quick lamination of different polymers with sterilization.

Keywords : Electron beam, Adhesion, Bio-medical, Dangling bond, Polypropylene, Polydimethylsiloxane

\section{INTRODUCTION}

現在、医療用高分子材料やそれらの複合材料の接着に は接着剤による接着や熱により溶着させる方法がある ${ }^{1,2)}$ 。溶着させる方法は、様々な形状で加工が可能で比較 的作業サイクルが早く、自動化が可能である。しかしな がら、局部的な加熱による材料特性の変化が懸念される 1)。一方、接着剤を用いた方法は接着が容易、安価、短 時間処理可能の長所がある。医療器具の場合、接着剤は

SAS Award was given to this paper presented as Poster Presentation at the 2010 SAS Intelligent Symposium.
患者に入る薬液や体内の体液に直接接触する接液部には 多使用されていないはずであるが、接着剤は揮発性物質 (VOC)などにより患者の体内環境に悪影響を及ぼすこと が懸念される2)。

殺菌効果があり、接着剂や熱溶着を用いずに短時間で、 人体に無害な高分子材料を接着することが出来れば、最 近の先端科学技術でさえも生じる想定外の問題を未然に 防ぐことができる安全な接着方法となりえる。

今回用いた低エネルギーの EB 照射処理はシリケート ガラスやポリカーボネート高分子材料のぬれ性向上や防

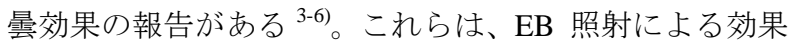


は不対電子の形成により、水分子を誘電分極し、クーロ ン引力が生じることで説明されている ${ }^{6)}$ 。また、高分子 材料の而照射損傷の改善も必要ではあるが、一般的に紫 外線照射の滅菌処理が数時間を要するのに対し、EB 照 射の滅菌処理速度は秒単位で終了し、医用・衛生技術と して有望である ${ }^{7,8)}$

ところで、異種高分子の接着では、表面エネルギーが 重要な因子となりえるという報告がある ${ }^{9}$ 。本研究室で 提案している低エネルギーの電子線(EB)照射による異種 高分子間の接着は従来の技術に比べ、滅菌作用が期待で き、短時間で接着することができる ${ }^{10)}$ 。このため、Fig. 1 のように、ワイヤレス診断機器を、生体適合性が高い親 水性高分子シートを疎水性高分子シートと接着した複合 シート材料で包装する応用が期待できる。

一方、ポリジメチルシロキサン(PDMS)は生体適合性高 分子として主にコンタクトレンズに用いられている ${ }^{11,12)}$ ポリプロピレン $(\mathrm{PP})$ は比較的強度が高く、ガス透過性に 優れ、人工心肺に用いられている ${ }^{13)}$ 。しかし、これらの 材料の接着は、表面エネルギーが著しく低く、接着剤や 熱溶着では十分な接着力が得られず問題となっている。

このような観点から本研究では難接着性の医療用異種 高分子材料に対して電子線照射接着処理を試み、PP と PDMS の接着部のはく離荷重を評価した。

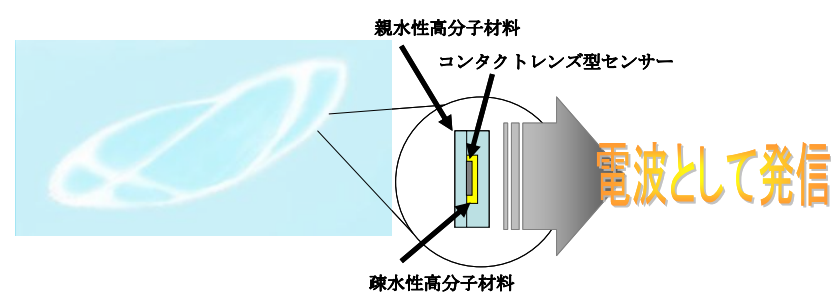

Fig. 1. Schematic diagram of application example.

\section{EXPERIMENTAL PROCEDURE}

\section{II-A Sample}

本研究の試料は PP フィルム(株式会社ピーワーク：

Clear Pack No.13)と PDMS フィルム(東レ・ダウコーニン グ株式会社 : DOW CORNING TORAY SILPOT 184 W/C) を用いた。

PDMS フィルムの試料形状は $10 \mathrm{~mm} \times 35 \mathrm{~mm} \times 0.075$ $\mathrm{mm} 、 \mathrm{PP}$ フィルムは $10 \mathrm{~mm} \times 35 \mathrm{~mm} \times 0.030 \mathrm{~mm}$ であった。 試料作製には PP フィルムと PDMS フィルムを接触させ た状態で試料台に置き、界面を脱気後、その上からナイ ロン保護フィルムで圧縮応力 $0.08 \mathrm{MPa}$ を印加した状態 で固定した。その後、EB をナイロンフィルム側から照 射し PP フィルムと PDMS フィルムの異種高分子同士を
接着させた。EB 照射後、ナイロン保護フィルムを取り 外した。この際、試料と保護フィルム間の接着は観察さ れない。

EB 照射処理には Fig. 2 に示すエレクトロカーテンプ ロセッサー(岩崎電気株式会社: Type CB175/15/180L)を用 いた ${ }^{4-7)}$ 。 $\mathrm{EB}$ 照射処理条件は加速電圧 $0.17 \mathrm{MV}$ 、照射電 流 $2.0 \mathrm{~mA}$ とし、EB 照射処理雾囲気は酸素濃度 $400 \mathrm{ppm}$ 以下の大気圧窒素雰囲気とした。窒素の流量は $1.5 \mathrm{~L} \mathrm{~s}^{-1}$ である。

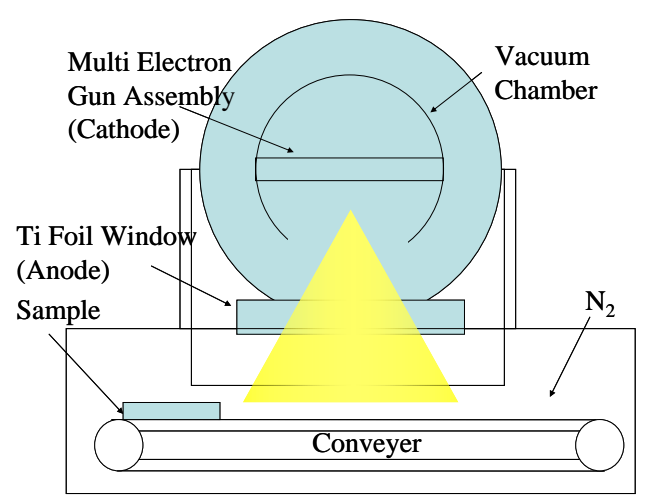

Fig. 2. Schematic diagram of electron curtain processer.

$\mathrm{EB}$ 照射は試料を $15 \mathrm{~cm}$ 角の純アルミニウムの試料フ オルダ上に置き、これをベルトコンベアに載せ、照射を 行い、コンベアースピードを $9.6 \mathrm{~m} / \mathrm{min}$ で処理した。温 度の上昇を避けるため、一回の照射時間を 0.23 秒と一定 とした。EB 照射線量は照射回数を増加することにより 照射線量を制御した。さらに、試料の片面に電子線照射 を行った。なお 1 回あたりの $\mathrm{EB}$ 照射線量は $43 \mathrm{~kJ} / \mathrm{kg}$ (kGy)であった。照射線量の校正は RCD 線量フィルム (FWT-60-00: FAR WESTTECHNOLOGY, カリフォルニ ア州) と吸光度測定用専用リーダー (FWT-92D: FAR WEST TECHNOLOGY, カリフォルニア州)からなるラジ オクロミックフィルムナイロン線量計を用いた。

\section{II-B T-peel Test}

本研究では PDMS フィルムと PP フィルムの接着強度 を評価するために、Fig. 3 に示すように接着試料の試験 片形状寸法を定め、はく離強度の評価を行った。強度評 価には微小荷重引張試験機(株式会社イマダ：F-S Master-1K-2N)を用い、負荷速度 $10 \mathrm{~mm} / \mathrm{min}$ で行った。 
PDMS (W:10 mm L:35 mm T:0.075 mm) PP(W:10 mm L:35 mm T:0.030 mm)

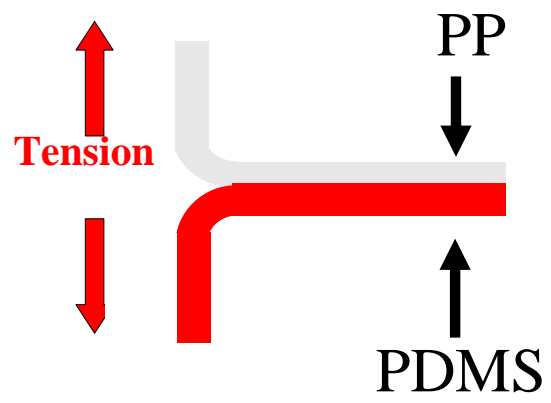

Fig. 3. Dimensions of T-peel test specimen.

\section{II-C ESR}

EB 照射処理による PP フィルムと PDMS フィルムの 不対電子の発生の有無を確認するために、電子スピン共 鳴装置 (ESR：日本電子株式会社：JES-FA200)を用いて 不対電子の有無を測定した ${ }^{14,15)}$ 。ESR の測定条件は試料 を石英製の試料チューブに入れ、X-band (周波数:9.4〜 $9.5 \mathrm{GHz}) 100 \mathrm{kHz}$ の変調磁場、室温で測定した。マイク ロ波の出力は $1.0 \mathrm{~mW}$ 、測定範囲は $317.0 \mathrm{mT}$ から 327.0 mT までとした。

\section{RESULTS}

\section{III-A Adhesive Peeling Force}

Fig. 4 に EB 照射接着させた PDMS と PP 複合フィルム のはく離荷重-はく離変位量曲線を示す。この曲線は大き く分けて 2 つの区間がある。Fig.4 中の微小区間(a)は、は く離の進展が開始寸るために必要な荷重での変形領域で ある。Fig.4 中の長い区間(b)は、実際にはく離が進展する ときの荷重での変形領域である。本研究では接着界面強 度に着目したため、はく離が進展する荷重での変形領域 である区間(b)を用い Table 1 にEB 照射線量とはく離の界 面強度の関係を示す。

この結果、未処理であっても接着を確認し、接着試料 のはく離荷重-はく離変位量曲線と平均接着荷重が得ら れた。

一方、EB 照射により接着荷重の向上を見出した。す なわち、未処理時の平均荷重が $7.0 \mathrm{~N} / \mathrm{m}$ であるのに対し、 $0.22 \mathrm{MGy}$ 照射の平均接着荷重は $23 \mathrm{~N} / \mathrm{m}$ であり、未処理 時よりも約 3.3 倍高い值を示した。

\footnotetext{
38 Journal of Advanced Science, Vol.23, No.3\&4, 2011
}

\section{DISCUSSION}

電子線照射前後の PP フィルムと PDMS フィルムの不 対電子の有無を電子スピン共鳴装置を用いて測定した。 $\mathrm{EB}$ 照射前後における PP フィルムと PDMS フィルムの ESR スペクトルの測定結果を Fig. 5(a) (b)に示す。

図より、PP フィルムと PDMS フィルム両方の未処理 試料には明確な ESR シグナルが観察されないことから、 試料中に不対電子がほとんど存在しない。

一方、照射した PP フィルムでは ESR シグナルが見ら れ、不対電子が存在することを見出した。すなわち、電 子線照射した試料中に不対電子が形成すれば、相手材表 面終端分子の誘電分極と、それに伴うクーロン引力が発 生し、接着強度が増大寸るため、はく離強度が向上した 可能性が考えられる。

一方、照射した PDMS フィルムでは明確な ESR シグ ナルが見られなかった ${ }^{16)}$ 。PP フィルムですでに不対電 子が形成しており、PDMS フィルム表面終端分子が誘電 分極し、それに伴うクーロン引力が発生していれば、接 着強度が増大し、はく離強度の向上が説明出来る。

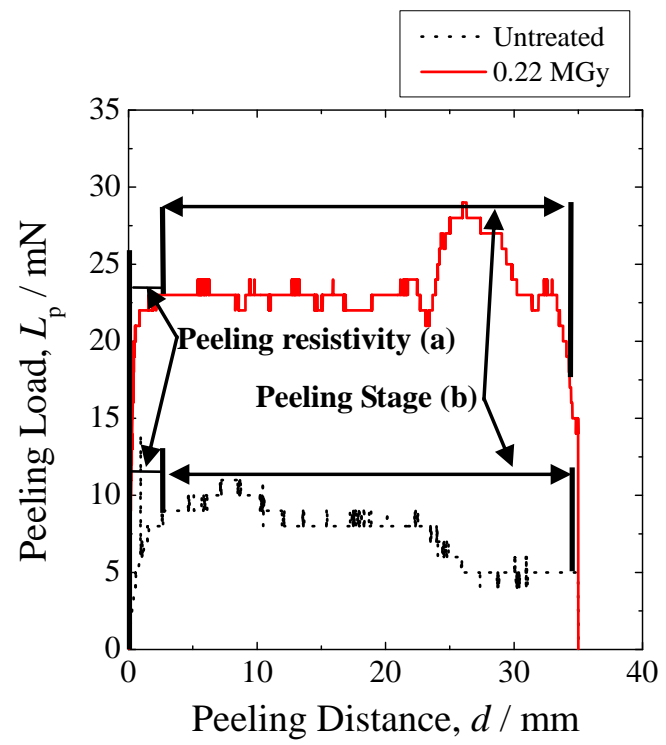

Fig. 4. Peeling load $\left(L_{\mathrm{p}}\right)$ - peeling distance $\left(d_{\mathrm{p}}\right)$ curves of untreated and $0.22 \mathrm{MGy}$ EB irradiated composites films laminated with PP and PDMS.

勿論、この効果だけでなく、微量な EB 照射により、ガ ラス遷移温度が低下し、高分子材料が軟化し、接着界面 での有効接触面性が増加し、接着荷重を高める可能性も 否定できない。

なお、試料作製には PP フィルムと PDMS フィルムを 接触させた状態で試料台に置き、真空排気後、その上か らナイロン保護フィルムで圧縮応力 $0.08 \mathrm{MPa}$ を印加し 
た状態で固定したが、ナイロン保護フィルムと試料との 間に電子線照射後、接着は生じていない。これは、ナイ ロン保護フィルムと試料との間の空気が多く存在し点接 触状態であることに起因する。

Table 1. Mean adhesive load of PP and PDMS laminated sheets before and after EB irradiationrradiation.

\begin{tabular}{|c|c|}
\hline $\begin{array}{c}\text { EB irradiation dose } \\
\text { D/MGy }\end{array}$ & $\begin{array}{c}\text { Mean adhesive Load } \\
F / \mathrm{N} \cdot \mathrm{m}-1\end{array}$ \\
\hline Untreated & 7.0 \\
\hline 0.22 & 23 \\
\hline
\end{tabular}

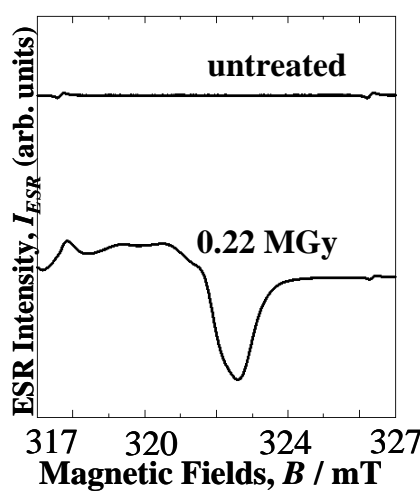

(a) PP

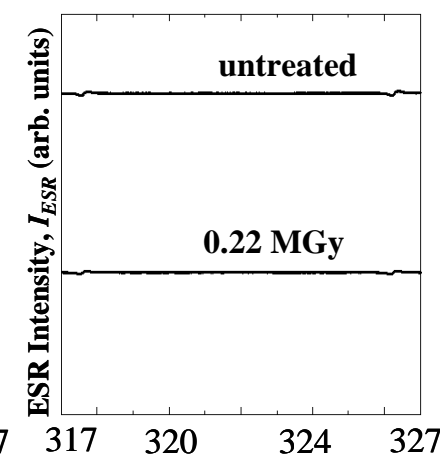

Magnetic Fields, $B$ / mT

(b) PDMS
Fig. 5. ESR signal on PP and PDMS with and without EB irradiation.

\section{CONCLUSION}

本研究ではPP フィルムと PDMS フィルムを用いた異 種高分子材料間の $\mathrm{EB}$ 照射による接着について検討を行 い、その接着試料のはく離荷重の変化を測定した。

1 : その結果、未処理試料よりも $\mathrm{EB}$ 照射後の接着試 料は高いはく離荷重を示した。0.22 MGyの EB 照射によ り接着させた PDMS と PP フィルムの接着強度を 3.3 倍 向上寸ることを確認した。

2 :照射したPP フィルムではESR シグナルが見られ、 不対電子が存在することを見出した。すなわち、電子線 照射した試料中に不対電子が形成すれば、相手材表面終 端分子の誘電分極と、それに伴うクーロン引力が発生し、 接着強度が増大寸るため、はく離強度が向上寸ると考え た。

よって本研究の技術は熱溶着が使えず、さらに接着剤 の使用が困難な場合に、EB 照射高速滅菌接着技術とし
て、有効な接着処理であることを確認した。

\section{ACKNOWLEDGEMENTS}

株式会社アイ・エレクトロンビームの方々に研究遂行 にあたり電子線照射の有益なご助言とご協力を戴いた。 ここに深謝の意を表する。東海大学 工学部 電気電子工 学科教授・庄善之先生に研究遂行にあたり ESR の有益な ご助言を戴いた。ここに深謝の意を表する。

\section{REFERENCES}

1 M. Kobayashi: Plastics. 41 (1990) 84-89.

2 T. Nakayasu and Y. Oohashi:Technology on Adhesion \& Sealing.46 (2002) 451-456.

${ }^{3}$ K. Oguri, K. Fujita, M. Takahashi, Y. Omori, A. Tonegawa, N. Honda, M. Ochi, K. Takayama and Y. Nishi: J. Mater. Res. 13 (1998) 3368-3371.

${ }^{4}$ K. Oguri, N. Iwataka, A. Tonegawa, Y. Hirose, K. Takayama and Y. Nishi: J. Mater. Res. 16 (2001) 553-557.

5 K. Oguri and Y. Nishi: Mater. Trans. 45 (2004) 1346-1349.

${ }^{6}$ K. Oguri, T. Takahashi, A. Kadowaki, A. Tonegawa, Y. Nishi: J. Japan Inst. Metals, 68 (8) (2004) 537-539.

7 A. Kasashima, N. Iwataka, J. Kawano, N. Honda and Y. Nishi: J. Adv. Sci. 9 (1997) 70-71.

${ }^{8}$ S. Kinoshita: J. Illum. Engng. Inst. Jpn. 91 (2007) 210-215.

9 T. Shimaru: Technology on Adhesion \& Sealing. 3 (1959) 121-130.

${ }^{10}$ H. Sato, K. Iwata, A. Tonegawa, Y. Nishi: J. Japan Inst. Metals. 72 (2008) 526-531.

${ }^{11}$ Y.Yokoyama and A.Yamauchi: Jpn. J. Mater. Sci. 30 (1993) 15-25.

${ }^{12}$ T. Yasuda: Electronic Materials. 44 (2005) 37-40.

${ }^{13}$ T. Maruya: Special Steel. 50 (2001) 32-33.

${ }^{14}$ Y. Nishi, A.Mizutani, A. Kimura, T. Toriyama, K. Oguri and A. Tonegawa: J. Mater. Sci. 38 (2007) 89-92.

${ }^{15}$ N. Yamaguchi, K. Oguri, A. Tonegawa and Y. Nishi: J. Japan Inst. Met. 68 (2004) 198-201.

${ }^{16}$ Y. Nishi, H. Kawazu1, H. Takei1, K. Iwata, H. Kudoh, K. Mitsubayashi: Mater. Trans. 52 (2011) 1943-1948. 